\title{
CEUZine: uma oficina de histórias em quadrinhos na UFSM
}

\author{
FÁBIO PURPER MACHADO
}

AYRTON DUTRA CORREA

\section{Resumo}

Aborda-se neste trabalho uma proposta de criação artística, realizada através uma oficina de Histórias em Quadrinhos com jovens da Casa do Estudante Universitário - UFSM. Analisa-se parte do material escrito disponível sobre a linguagem dos Quadrinhos, sob a perspectiva da Cultura Visual. Apresenta-se uma descrição dos métodos da pesquisa e suas aplicações, juntamente com reproduções de obras que foram produzidas no decorrer da oficina, pensando-se as imagens e suas reverberações no contexto de seus criadores. 


\title{
CEUZine: a comics workshop at UFSM
}

\author{
FÁBIO PURPER MACHADO \\ AYRTON DUTRA CORRÊA
}

\begin{abstract}
This work deals about a proposition of artistic creation, done through a comics workshop amongst young people from the Student's House of UFSM. Here we analyze some of the available written material about the comics' language under the perspective of Visual Culture. We also present a description of the research methods and their applications, alongside with reproductions of pieces which were produced during the workshop, thinking about the images and their reverberations on their creators' context.
\end{abstract}




\section{Introdução}

O uso da imagem pelos contadores de histórias remonta às origens da humanidade. Através dos animais nas paredes da caverna, dos murais narrativos egípcios, da cerâmica grega, da escultura cênica africana, dos mosaicos e iluminuras medievais e afrescos renascentistas, mitologias, ideologias e morais têm sido passadas de geração a geração. Vivemos hoje uma proliferação gigantesca de todo tipo de narrativa imagética, através dos meios de comunicação, impressos ou eletrônicos: revistas, internet, cinema, televisão, jogos eletrônicos... Todos estes trazem novas mitologias, numa constante reciclagem dos símbolos das antigas, e podem representar tanto um meio de instrumentalização do mundo quanto de doutrina e alienação.

Entretanto, o segundo caso predomina, pois no geral as produções suscitadoras de certa crítica são escamoteadas pelos meios de comunicação de massa, que costumam privilegiar as que priorizam uma doutrina voltada a interesses do capitalismo. Faz-se útil, então, uma educação voltada a um fazer contextualizado de uma dessas formas narrativas visuais, no caso, a história em quadrinhos, por ser um meio de grande popularidade e de produção economicamente viável, e também por ser uma linguagem com a qual pessoalmente tenho certa familiaridade e prática.

Este texto se refere a meu Trabalho de Conclusão do curso de Artes Visuais: Licenciatura Plena em Desenho e Plástica, em uma oficina para jovens com ensino médio completo ou superior incompleto. É uma das etapas de uma pesquisa - realizada também em dois ambientes escolares, uma 8‥ Série do ensino formal e uma oficina do projeto Escola Aberta - por meios de utilizar as Histórias em Quadrinhos como subsídio para a docência em Artes Visuais. 


\section{Os temas}

\section{Cultura Visual}

Os estudos de Cultura Visual se constituem de um campo adisciplinar que, segundo um de seus principais autores, o professor da Universidade de Barcelona Fernando Hernández (2000), abarca a história, a semiótica, a psicologia cultural, a antropologia e os estudos culturais, de gênero, de mídia e cinema, convergindo num questionamento das fronteiras entre essas disciplinas. Tais estudos surgem no final da década de 1980 quando a história da arte começa a deixar de enfatizar o autor, a obra e sua produção, para dar maior importância a seu processo de distribuição e recepção, ou seja, à sua repercussão junto ao público através dos tempos.

Leonardo Charréau (2007) constata ainda hoje a presença forte do preconceito para com o estudo da imagem por parte da chamada alta cultura, que considera esta como mera ilustração para um saber que só poderia ser concretizado textualmente. Definindo visualidade como "ver em contexto", culturalmente (diferenciando-se do ver fisiológico), o autor trata a contemporaneidade como um momento em que a sociedade troca sua estrutura de "produção de coisas" por uma de "produção de informação", devido à relativa democratização da fotografia, do cinema, da televisão e da internet, que possibilita, diferentemente da imagem globalizada à força, uma imagem global, criada, e muitas vezes minuciosamente calculada, já no intuito de ser compartilhada, e, com isso, potencial portadora de carga doutrinária.

Hernández (2000, p. 38) define Cultura Visual como um estudo que analisa não apenas o contexto das produções da História da Arte, "mas também da sua distribuição e recepção; (...) não tanto a leitura das imagens como as posições subjetivas que produzem as representações mediadas pelas imagens", e que "é uma referência para pensar de forma crítica o momento histórico no qual vivemos e revisar o olhar com o qual construímos o relato sobre outras épocas a partir de suas representações visuais". Substitui 'o que se vê e o que se pode interpretar dessa imagem' por "como essa imagem me vê, (...) como interpreta e posiciona quem a fez, quem a comprou, quem a viu em sua época e nós".

Pode $o$ arte/educador desmistificar verdades impostas pelos ícones doutrinários que impregnam nossa cultura? Podem estes mesmos artefatos ser usados de forma a fomentar uma 
discussão, um pensar a respeito deles mesmos e do próprio sistema de onde se originam? Esta pesquisa, embasada nos estudos de cultura visual, não tem a pretensão de responder estas questões, mas sim de desenvolvê-las.

\section{Arte Seqüencial e Histórias em Quadrinhos}

Define-se por arte seqüencial qualquer artefato cultural que se utilize de seqüências de imagens para estabelecer uma experiência narrativa. Entre as surgidas com a reprodutibilidade técnica conquistada desde a Revolução Industrial, estão as histórias em quadrinhos na forma em que as conhecemos, o cinema e a animação. Escolhi me deter, por proximidade e acesso, à prática da primeira destas linguagens, dotada de uma estética especial, embora até hoje pouco legitimada entre os teóricos da arte.

O escritor, desenhista e teórico da Arte Seqüencial, Will Eisner, um escritor fundamental para o reconhecimento dos quadrinhos como arte ressalta em suas publicações a necessidade de legitimar as histórias em quadrinhos como linguagem artística, ao lado de sua cria direta, o cinema.

Felizmente, o grande aumento do número de artistas e escritores sérios que migraram para os quadrinhos serve de testemunho do potencial dessa mídia. E tenho convicção de que o conteúdo das histórias será o propulsor do futuro das revistas em quadrinhos. (EISNER, 2005, p. 10)

Suas obras sobre a estética e narratividade dos quadrinhos mostram ser, ao lado das de Scott McCloud, um material didático rico em possibilidades para a utilização na aprendizagem de artes visuais através das narrativas gráficas. Segundo McCloud, a linguagem dos quadrinhos se define basicamente como "a ideia de posicionar uma imagem após outra para ilustrar a passagem do tempo". (2000, p. 1) O autor explica que

Em seu uso da seqüência visual, os quadrinhos substituem o tempo pelo espaço. No entanto, não existe uma norma de conversão, e o tempo flui nos quadrinhos de uma enorme variedade de maneiras. Com imagens inertes que estimulam um único sentido, os quadrinhos representam todos os sentidos, e pelo caráter de suas linhas, representam o incrível mundo da emoção. Linhas que evoluem ese tornam elas próprias símbolos, ao dançarem com os símbolos mais jovens chamados palavras. (MCCLOUD, 2000, p. 2) 
Os primeiros escritos nacionais a abordarem a importância e as possibilidades dos quadrinhos como forma de arte, realizados por Moacy Cirne, analisam indicadores sócio-econômicos que derrubam a famigerada associação dos quadrinhos à delinqüência juvenil, e abordam também a estética dos balões, onomatopéias e ritmo visual. Antes mesmo da formalização da Cultura Visual como campo de estudos, Cirne enfatiza a relevância histórica das HQs por seu uso como reforçadores da ideologia pequeno-burguesa, individualista, da qual nasceram impregnados, mas principalmente por terem, "em contradição dialética, colocado em xeque toda a ossatura da arte ocidental". (1970, p. 19) Considerando que nesta linguagem podemos encontrar tanto uma alta informação literária, quanto consideráveis explorações metalingüísticas, suas possibilidades de criação transcendem a mera definição de ópio literário.

\section{A oficina}

Através do espaço da oficina, busco observar as possibilidades expressivas advindas do contato dos colaboradores com um fazer contextualizado dentro da linguagem das histórias em quadrinhos, com suas potencialidades artísticas e sua íntima relação com a Cultura Visual.

Busquei nesta pesquisa abrir um espaço de produção coletiva em arte seqüencial, através de uma oficina, como definida por Guilherme Corrêa:

Um dos pontos mais importantes da oficina, como estratégia em educação, é a ligação do oficineiro com o tema que escolhe. (...) Interesse que independe de obrigações que possa ter com o cumprimento de currículos ou por força de sua formação. (...) A oficina inicia-se quando se quer conhecer algo. A pesquisa, todavia, só vai resultar em uma oficina quando se queira mostrar aos outros - qualquer um - o resultado do seu estudo. (CORRÊA, 2006, p. 27-28)

O sistema de ensino escolar é, em seu cerne, defasado no sentido de mobilizar uma real experiência de aprendizagem. $\mathrm{Na}$ oficina, a lógica do ensino compulsório da escolarização perde seu sentido, pois se promove um ambiente onde as pessoas compartilham vivências e fazeres, e com isso desenvolvem um conhecimento sobre determinado assunto que elas mesmas buscaram ao iniciarem a atividade. 
Organizar grupos de pesquisa em que as diferenças entre os participantes não se dêem pelas posições hierárquicas demarcadas pela instituição e nem pela hierarquização dos saberes, naturalizada pelos programas de ensino, é o centro ativo deste tipo de pesquisa que tem como força o conhecer com vontade. (CORRÊA, 200o, p. 186)

Como propositor da oficina, espera-se do pesquisador que tenha, ainda que com determinada dose de flexibilidade, rumos pré-definidos para as atividades. Da "Pedagogia Questionadora", (Barbosa, 2006, p. 8-9) impulsionada por um "diálogo no qual não há resposta certa nem errada", cria-se a metáfora do Zig/Zag: "contextualização tanto para o fazer quanto para o ver". Os procedimentos projetados para cada encontro oscilam entre as práticas discursivas e a criação plástica, numa relação aberta a possibilidades de modificação sugeridas por qualquer dos participantes.

Procuro, nesta abordagem qualitativa, não cair no paradigma pesquisador / pesquisado / coleta de dados, e sim construir um processo em grupo com os participantes do projeto. Marcondes (2008, p. 464) ressalta o convívio como fator importante desse processo: compartilhar "de forma mais completa possível dessa realidade que investiga, participando dos hábitos sociais, dos rituais, das práticas cotidianas."

Martins (2006, p.51) afirma que "diferentemente das outras Ciências, a Humana não recebeu por herança um domínio já delineado", por fundamentar-se no modo de ser do homem. Também segundo ele, sendo os conceitos produzidos pelas descrições, "um fato que seja do domínio apenas do pensamento ou da imaginação dificilmente pode constituir objeto de descrição" (p. 54). A incerteza dos resultados de uma pesquisa com grupos de seres humanos oriundos de contextos nem sempre semelhantes e com histórias de vida, psiquê e potencialidades provavelmente muito mais distintas justifica sua abertura, sua flexibilidade e necessidade de envolvimento.

Em uma oficina semanal, acompanhei um grupo de cinco estudantes, universitários ou em idade equivalente, moradores ou freqüentadores das Casas do Estudante I e II da Universidade Federal de Santa Maria, com graus de contato diferenciados, uns dos outros, com a arte seqüencial dos quadrinhos. Da pessoa com o mínimo de contato àquela que já "se aventurou" nas HQs, formei um grupo heterogêneo de onde procurei obter referências valiosas para um estudo sobre a cultura visual destes. 
Através da produção realizada em diferentes linguagens (desenho, modelado, colagem, fotografia), busquei propor a construção de narrativas imagéticas (HQs) pelos colaboradores, reunidas ao final dos encontros num zine, que abre espaço a discussões dobre a Reprodutibilidade Técnica da Arte, assim como a Cibercultura.

Faço uso da monografia do colega Ivan Kappaun - também sobre arte-educação através dos quadrinhos, mas sob uma abordagem mais bibliográfica - onde se encontram definições por ele pesquisadas, entre elas a do zine, ou fanzine,

uma revista em quadrinhos amadora, feita de forma artesanal a partir de máquinas de xérox ou mimeógrafos. É uma alternativa barata àqueles que desejam produzir suas próprias revistas para um público específico, e conta com estratégias informais de distribuição. Diversos cartunistas começaram desta maneira antes de passarem para espécies mais tradicionais de publicação, enquanto outros artistas estabilizados continuam a produzir fanzines paralelamente a suas carreiras. (KAPPAUN, 2008, p. 21)

O zine funciona, nesse estudo, como uma síntese da apreensão da visualidade artística por parte dos colaboradores. Através da coletânea das narrativas criadas, pode ser facilitada uma compreensão a respeito da visão de mundo dos participantes, e também uma divulgação dos resultados expressivos obtidos com a experiência.

\section{Os encontros}

A pesquisa se deu durante o primeiro semestre de 2009, entre os meses de abril e julho. A ordem das atividades para cada encontro, a partir do segundo, foi sendo escolhida por votação ou consenso, conforme o andamento destas.

No primeiro encontro, a apresentação, em torno de uma caixa com revistas e livros, teve incluídas indagações sobre Arte, e, especificamente, quadrinhos, e sobre Cultura Visual. A apresentação de imagens precedeu o fazer, mais ou menos livre, de uma página de HQ. Solicitei que contassem qual o contato que tiveram com a linguagem dos quadrinhos e com questões da própria arte até então. Cito aqui parte de seus depoimentos.

Acadêmico dos últimos semestres do curso de Geografia da UFSM, o participante Fres declarou que a HQ faz parte da sua história: "Parte do que eu sou é graças à revista em qua- 
drinhos: meio maniático..." Entre suas preferências destacou Hulk, Wolverine e X-Men.

Eu morava num lugar muito pequeno. Tinha uma livraria na cidade, e a dona me conhecia. No momento que meu pai trouxe um gibi eu me viciei, li umas cinco vezes, aí fiquei sabendo que a livraria tinha gibi. Eu ia lá e comprava, de preferência se fosse de super-herói, se não tinha eu comprava outro. Mas nunca conseguia ler em seqüência.

Presente no discurso da maioria dos colaboradores está a dificuldade encontrada ao se "pegar o bonde andando" numa história publicada da forma seriada usada pelas editoras do gênero dos super-heróis. Fres lembra o arco de histórias Crise nas Infinitas Terras, da editora DC Comics (publicado no Brasil pela Editora Abril), em que as narrativas dentro de cada publicação alternavam entre diferentes dimensões paralelas: "quando eu começava a entender a história, acabava a revista".

O participante Riko, formando do curso de Química Industrial na UFSM, relatou seu primeiro contato significativo com a HQ:

Tinha uns 10, 12 anos, nunca me esqueço: Indo pra Faxinal (do Soturno, RS), paramos na rodoviária de Santa Maria. Eu incomodando a mãe, pra parar de incomodar, nós passamos na frente da banca e a mãe: "Te dou uma revista, tu pára quieto?" "Tá. Paro quieto". Tinha um monte de revistas. Isso era 94. Aí eu olhei assim, "Pá, eu quero aquela do Homem-Aranha". O cara da banca podia ter perguntado "qual do Homem-Aranha tu quer?", mas pegou a primeira que tinha e deu, e era a Homem-Aranha $2099 \mathrm{n}^{\circ} 14$.

Referia-se a uma série de publicações chamada Marvel 2099, no Brasil também publicada pela Abril, em que as histórias eram recriações de personagens conhecidos dentro de um universo futurista. O relativamente curto número de edições deste arco permitiu que Riko o colecionasse e pudesse ter uma compreensão aprofundada do funcionamento deste universo específico. Relacionando isto ao já citado problema da seriação, "gostei da 2099 porque peguei tudo do início."

O participante Aranha, então suplente do concurso vestibular para a Licenciatura em Artes Visuais, demonstra ter tido considerável contato com a arte, já tendo produzido certa quantidade de desenhos a nanquim e participado de produ- 
ções teatrais. Alegou ter lido histórias do Homem-Aranha das décadas de 70 e 8o, Mônica, Pato Donald das décadas de 60 e 50, Demolidor, e chamou a atenção para um grupo de super-heróis da Editora Marvel Comics chamado Excalibur. "Umas histórias meio psicodélicas, nunca entendi qual é que era, mas achava muito massa." O debate, neste momento, se centrou nas questões da seriação e na preferência declarada dos participantes pelo tipo de personagem - exemplificado por Conan, Justiceiro e Wolverine - que se define como anti-herói, ou seja, o protagonista que não demonstra gestos puros, justos e heróicos, mas sim uma personalidade em alguns agressiva, em outros fora da lei, mas principalmente, humana, falível e "politicamente incorreta".

O colaborador Jonas, estudante do Colégio Politécnico da UFSM, disse ter lido, em sua infância, Mickey e Pato Donald, e depois tomado "rumos bem diferentes, bem longe do quadrinho". Falando de arte, "sempre curti bastante desenhar. Nunca tive muita habilidade, nem pintava, mas me entretia. Fazia os trabalhos de Educação Artística com gosto", mas a linguagem era basicamente desenho, de escultura só teve teoria. Considera a informática como algo que $o$ afastou das artes.

A alfabetização do participante Matheus, então calouro do curso de História na UFSM, se deu através das HQs.

Começou tri cedo, até porque eu aprendi a ler lendo quadrinhos. Meu pai e meu avô traziam várias. Primeiro traziam, quando eu era pequeno, de personagens da Disney, da Turma da Mônica, depois os Faroestes italianos como Tex. Meio que me viciei, tinha uma coleção da Mônica quando era pequeno. Chegou uma idade, mais ou menos uns 11 anos, que eu me enjoei daquilo ali e parti pros quadrinhos de heróis. Colecionava Marvel e DC, "formatinho", depois Image, e Conan. Como base foi isso. Agora leio bem pouco, mas ainda gosto.

Sobre sua relação com a arte, alega que:

A partir dos quadrinhos comecei a ter contato com revistas e também literatura, e cinema. Já gostei de desenhar desde pequeno, e pensava em, quando crescer, trabalhar com alguma coisa que tivesse algo a ver com isso. Meu pai é pintor de casas, de letreiros, e os desenhos ele me chamava pra fazer, pra ele pintar. 
Com este relato demonstra ter tido contato com um método de trabalho em equipe semelhante à divisão entre desenhista e arte-finalista dos quadrinhos. "Depois de um tempo perdi bastante interesse, e agora só leio aquilo que eu gosto bastante." As trajetórias relatadas demonstraram variações em relação ao grau de contato com os quadrinhos, mas em comum o interesse mais inclinado ao gênero dos super-heróis.

Após os participantes terem compartilhado um pouco da relação entre sua história e os quadrinhos, procurei expor elementos relevantes de minha pesquisa dentro desta linguagem, através de imagens digitais de páginas de diferentes gêneros de quadrinhos: Cartum, obras de humor satírico ou crítico, do cotidiano, apropriações ou subversões históricas e literárias, contos policiais ou de suspense, narrativas orientais e européias, alguns underground brasileiros e obras que de diferentes formas revolucionaram e proporcionaram uma revitalização ao gênero de super-heróis.

Conversamos sobre as possibilidades da arte seqüencial, através destas imagens e das devidas explicações sobre o contexto delas, e então encerrei o encontro fazendo um breve resumo dos planos para os encontros seguintes, a fim de manter no grupo uma liberdade de escolha de ordem, e pedindo que trouxessem, no encontro seguinte, uma história criada por eles, com temática e grau de acabamento totalmente livres.
Figuras 1 e 2

Narrativas realizadas pelo participante Aranha.
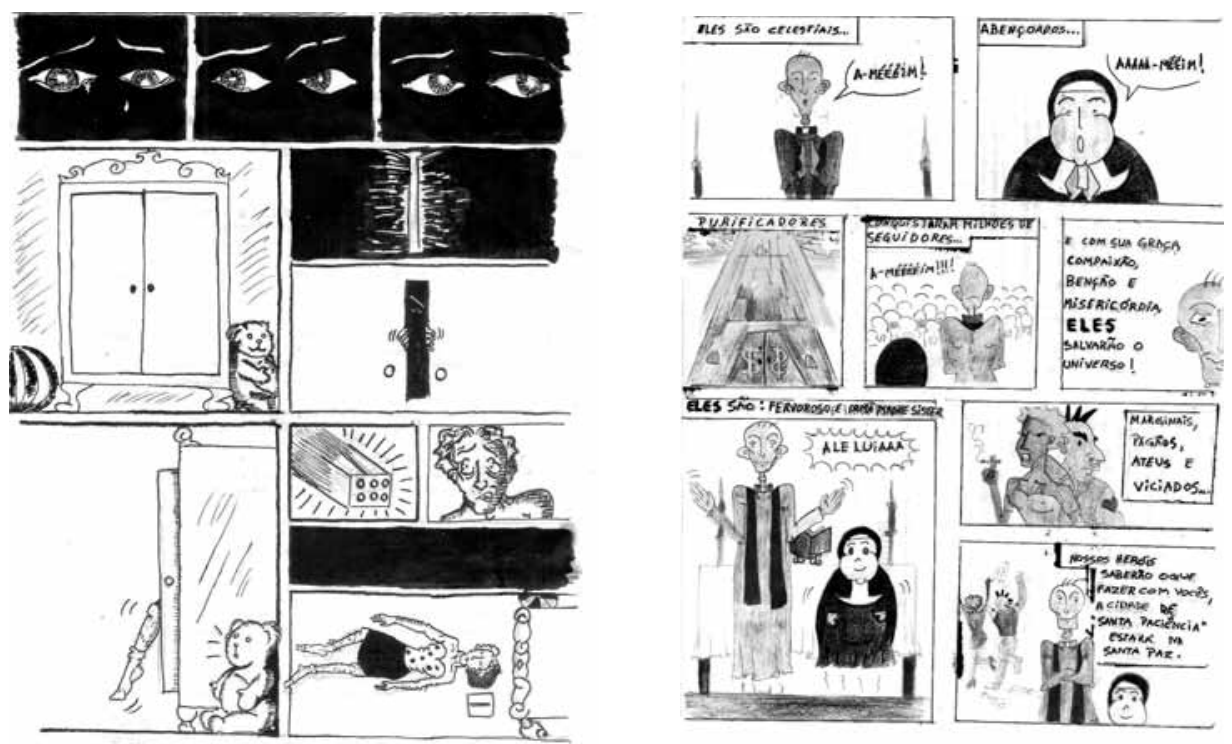
Dois dos participantes escolheram, para este trabalho, usar como tema fatos do cotidiano, usando eles mesmos como personagens, com caneta esferográfica: Jonas inicia o relato "A porta que não abria por fora", sobre uma ocasião em que havia saído e se esquecido de levar consigo a chave de seu apartamento, no terceiro andar da CEU II. "Orrú", a narrativa de Riko, traz uma ocasião de saída do Restaurante Universitário (RU) - UFSM, em que ele se detém para ler o mural de recados - que parodia escritos cotidianos deste: "divido apê", "palestra" e "iu ispique inglis?" - e seus amigos, apressados, brincam "Que tu ta fazendo? Afinal tu nem sabe ler!". Sua resposta, "eu gosto de ver as figuras, bando de pau-mandado! Ainda aprendo lê", remete à questão do analfabetismo e à própria problemática da distinção cultural entre imagem e texto, questões históricas nos debates sobre a influência dos quadrinhos na educação. Aranha apresentou três obras: uma sátira ao clero - Padre Fervoroso e Irmã Madre Sister - utilizando elementos da propaganda e do gênero dos super-heróis, a grafite e lápis de cor, e outras duas narrativas sem palavras, a nanquim, entre elas uma sensível alegoria a questões de sexualidade, utilizando a popular metáfora do "sair do armário". O humor foi elemento comum à maioria das obras apresentadas.

Da ideia de que uma pequena história pode ser uma metáfora para vastos conceitos, além das primeiras aparências, partiu um segundo encontro com apreciação de imagens e debate sobre a Alegoria, seguidos da criação (escrita ou desenhada) do argumento de uma história alegórica. Embasei-me na obra "A Palavra Mascarada", de Maria Zenilda Grawunder, para este tema. Após o debate gerado por estas imagens, solicitei para o domingo seguinte que criassem histórias que pudessem ser tidas como alegorias. Para os que ainda não haviam realizado a primeira atividade, somaram-se as ideias, na proposta de uma HQ com elementos alegóricos.

Entre os trabalhos apresentados nos encontros seguintes, a HQ de Fres, desenhada a grafite, trazia o skate, elemento de seu cotidiano, uma diagramação elaborada e um belo uso da metalingüística: o personagem se segurando na borda do quadrinho para não cair na água. $\mathrm{O}$ participante Aranha seguiu sua paródia em mais duas páginas de história, agora a nanquim, esferográfica e lápis de cor, incorporando elementos do cotidiano, como o leite condensado sendo comido na lata, como uma alegoria aos vícios, aos pecados que os também alegóricos super-heróis clericais teriam a missão de combater. A publicidade continua, "com o oferecimento da Água Benta 

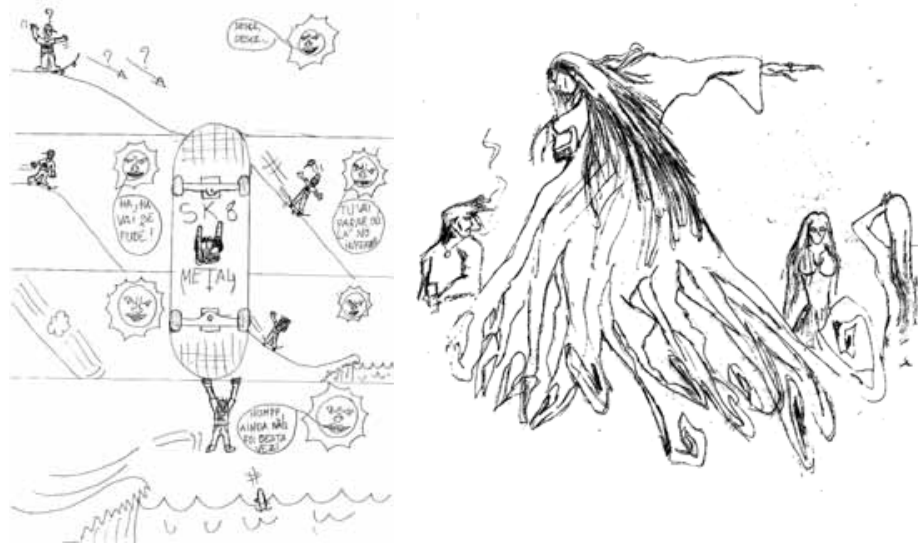

Figura. 3 - Narrativa de Fres

Figura 4-Desenho de Matheus.

XVI, a bênção no seu sistema urinário", incorporando em sua sátira referências ao atual papa da igreja católica e à comercialização de itens tidos como sagrados.

A "Ansiedade da Aproximação" de Matheus conta com um grafismo vigoroso, um traço que mais uma vez utiliza exagero nos ângulos, e expressa a timidez que este alega ter. Riko, novamente como protagonista, se vê na fila do RU, conjecturando com amigos sobre o cardápio do dia, uma situação cotidiana, exceto pelo detalhe de todos os personagens serem bovinos. Ele desperta e diz "Que pesadelo pirado!", mas a questão social, política, fica no ar. "Quem é o gado?" E, por fim, uma fotonovela criada digitalmente por Aranha, com edições de fotografias tiradas por ele e seus amigos em vernissages, eventos realizados como aberturas de exposições artísticas, satiriza as mesmas e a própria relação do público e dos artistas com a arte.

Fig.ura 5 - Desenho de Jonas

Figura. 6 - Desenho de Riko
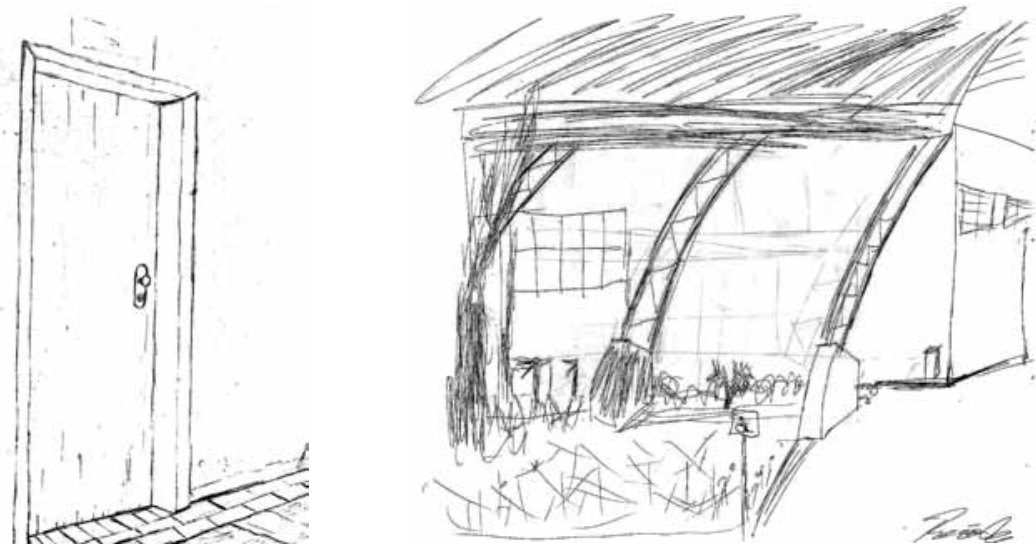

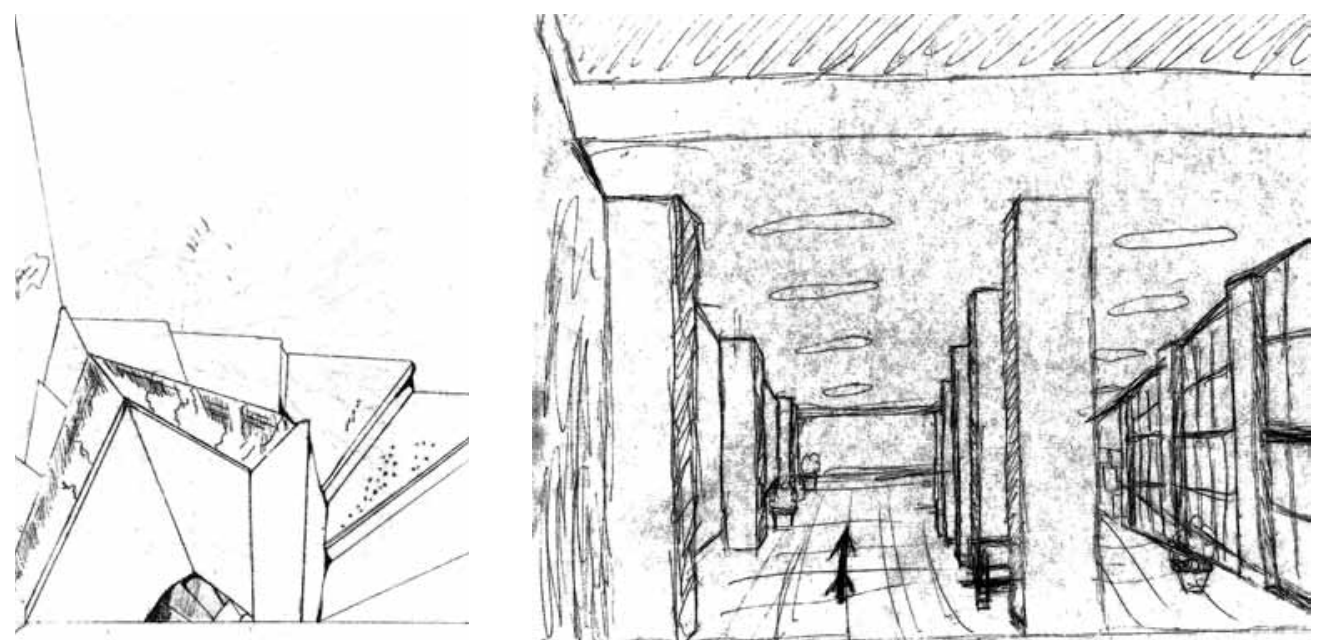

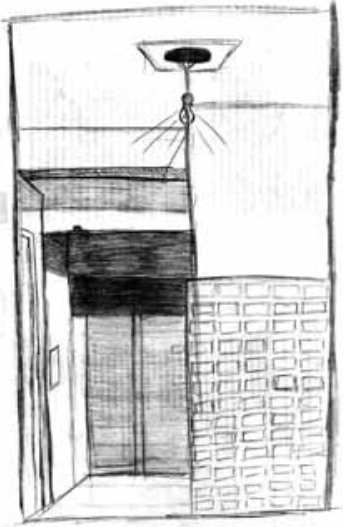

Figura 7 Desenho de Matheus

Figura 8 Desenho de Fres

Figura. 9 Desenho de Aranha

O terceiro encontro foi destinado à relação da imagem cotidiana com o fazer artístico, desenhando elementos da CEU II e arredores, e debatendo possibilidades de cenários extraídos do cotidiano para os quadrinhos produzidos. Procurei desta experiência verificar o contato do grupo com noções de geometria, através do desenho de observação das dependências do Campus.

Cada um dos desenhos feitos demonstrava domínio em certos aspectos: a perspectiva de Fres ao desenhar a área em frente à União Universitária onde costuma praticar manobras de skate, a quantidade de desenhos feita por Riko, de diferentes ângulos do cenário escolhido, o RU-UFSM e proximidades, o esmero de Jonas em desenhar uma porta, personagem essencial de seu enredo, a tendência geométrica e angulosa de Matheus e sua atenção a detalhes como o banco quebrado, potencial coadjuvante para alguma $H Q$, e a inventividade de Aranha ao usar uma porta como janela de enquadramento. Ao final deste encontro, conversamos sobre as potencialidades de uso dos cenários desenhados para as histórias, tanto as já feitas como as que poderiam surgir.

No quarto encontro, destinado à criação escultórica, assistimos a um trecho da animação "As Bicicletas de Belleville", de Sylvain Chomet, onde vemos um garçom em movimentos acentuadamente curvos, e analisamos imagens de obras que utilizam a relação homem-bicho, tanto por substituição (Disney, Spiegelman, Ensor), quanto por aproximação ou hibridação de feições (Eisner, Bosch, Picininni). Também distribui uma fotocópia do "Microdicionário de gestos", da obra "Quadrinhos e Arte Seqüencial” de Will Eisner (1989, p. 102), pro 


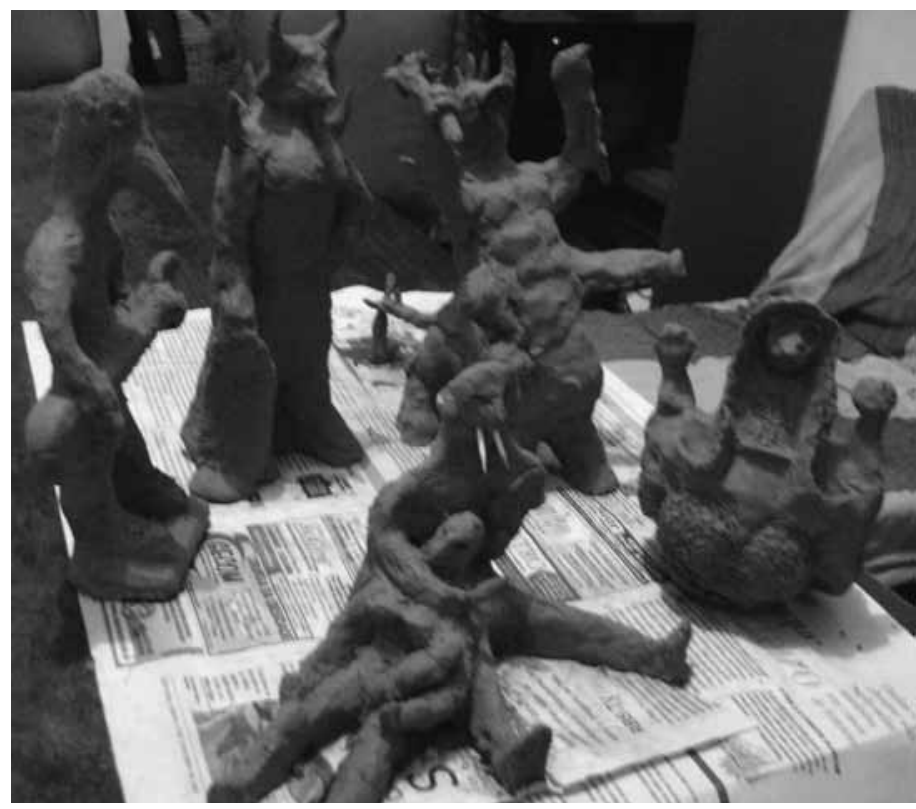

pondo o modelado em argila, utilizando personagens já existentes ou não nas histórias em desenvolvimento, tendo como subsídio a associação destes a algum animal, e procurando conferir às obras movimento, expressividade gestual e corporal, questões interessantes de serem exploradas em escultura. As obras realizadas demonstraram um bom entendimento da proposta. Numa mesa forrada com folhas de jornais, os participantes realizaram modelados desafiadores: o corvo guitarrista de Jonas inicialmente teria maior magreza caricatural, com pernas mais alongadas, mas foi reestruturado, ainda assim mantendo sua expressividade. Riko modelou, inspirado na estética de jogos sobre mitologia grega, um centauro para ser o vilão de sua alegoria dos bovinos na fila do Restaurante Universitário. Fres seguiu no tema de sua história e criou um demônio skatista. Aranha transformou sua personagem Irmã Madre Sister numa figura híbrida galinácea e Matheus desenvolveu sua alegoria da aproximação ao nível do suspense, com sua cena romântica monstruosa. Ao final foi sugerida a fotografia de diferentes ângulos dos personagens para planejar seu possível enquadramento em futuras histórias, através de desenho de observação ou de montagem fotográfica. O participante Jonas realizou uma edição computadorizada da imagem de seu corvo guitarrista, feita com a finalidade de proporcionar à fotografia um acabamento gráfico próximo ao do desenho.
Figura 10

Da esquerda para a direita, modelados de Jonas, Fres, Riko e Aranha, à frente o de Matheus. 

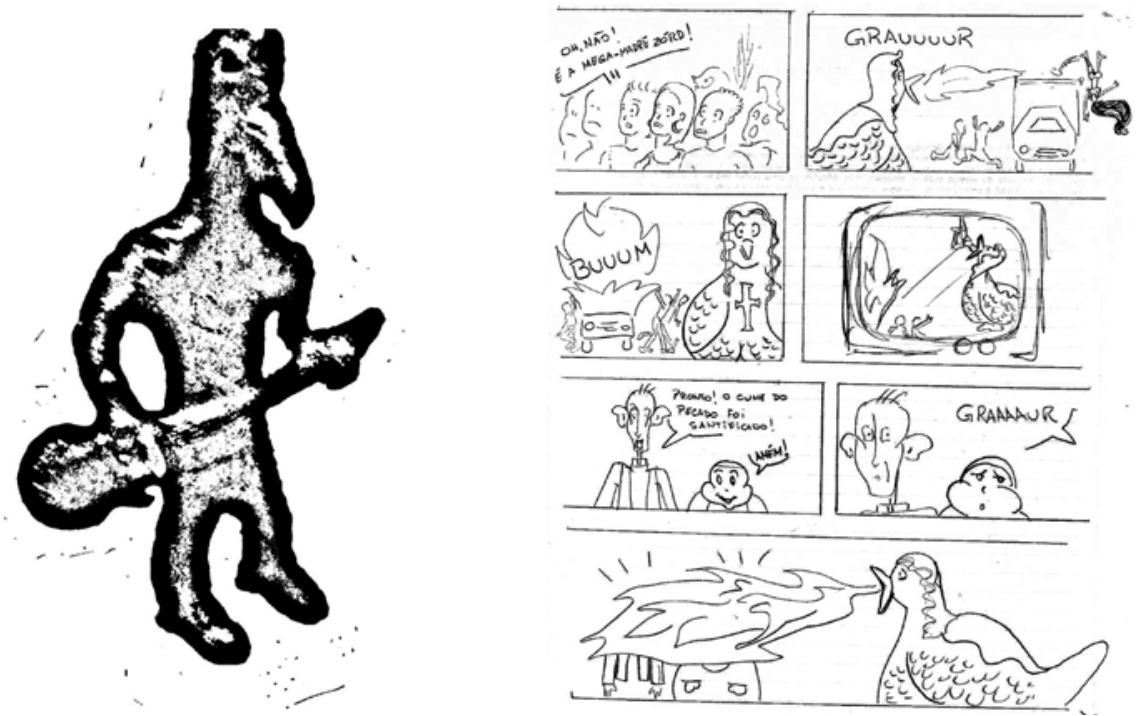

Figura 11

Edição fotográfica de Jonas

Figura 12

Página da narrativa de Aranha

Outro fruto desta proposta foi uma história de três páginas do participante Aranha, onde surgia uma paródia às super-sentai japonesas (séries filmadas em que heróis protegem a terra de monstros gigantes utilizando robôs de mesmo tamanho). Utilizando a expressão zord (que denomina os robôs da série Power Rangers, transmitida no Brasil desde os anos 1990 pela rede Globo), nomeou sua escultura a Mega-Madre Zord, desenhando-a como uma criatura gigante usada para destruir um trio elétrico de carnaval que incitava o uso de preservativo, numa oposição a valores propagados pelo clero. Nesta obra a sátira encontra um peso escatológico quando um menino sai engatinhando de baixo da batina do personagem Padre Fervoroso, após um chamado "relaxamento eclesiástico".

No quinto encontro, a linguagem da apropriação foi abordada, inicialmente discutindo conceitos do movimento dadaísta e imagens das questões estéticas dos quadrinhos nas abordagens de Will Eisner e Scott McCloud, e após, na criação de uma página de HQ-colagem com imagens de revistas, jornais, etc. A estética (dos balões, onomatopéias e da própria diagramação) dos quadrinhos foi utilizada ao lado de algumas noções de harmonia, e do uso de imagens da mídia, do cotidiano, para fins expressivos.

Vemos no trabalho de Fres a quebra de uma regra da seqüência narrativa ocidental: as falas acontecendo da direita para a esquerda remetem à narrativa do mangá, o quadrinho japonês. Ao ser lembrado sobre isso, o participante escolheu utilizar setas 
para indicar a seqüência de leitura. Sua área de estudos, a Geografia, se mostra presente nesta obra que evoca questões políticas como o feminismo, e científicas como o evolucionismo.

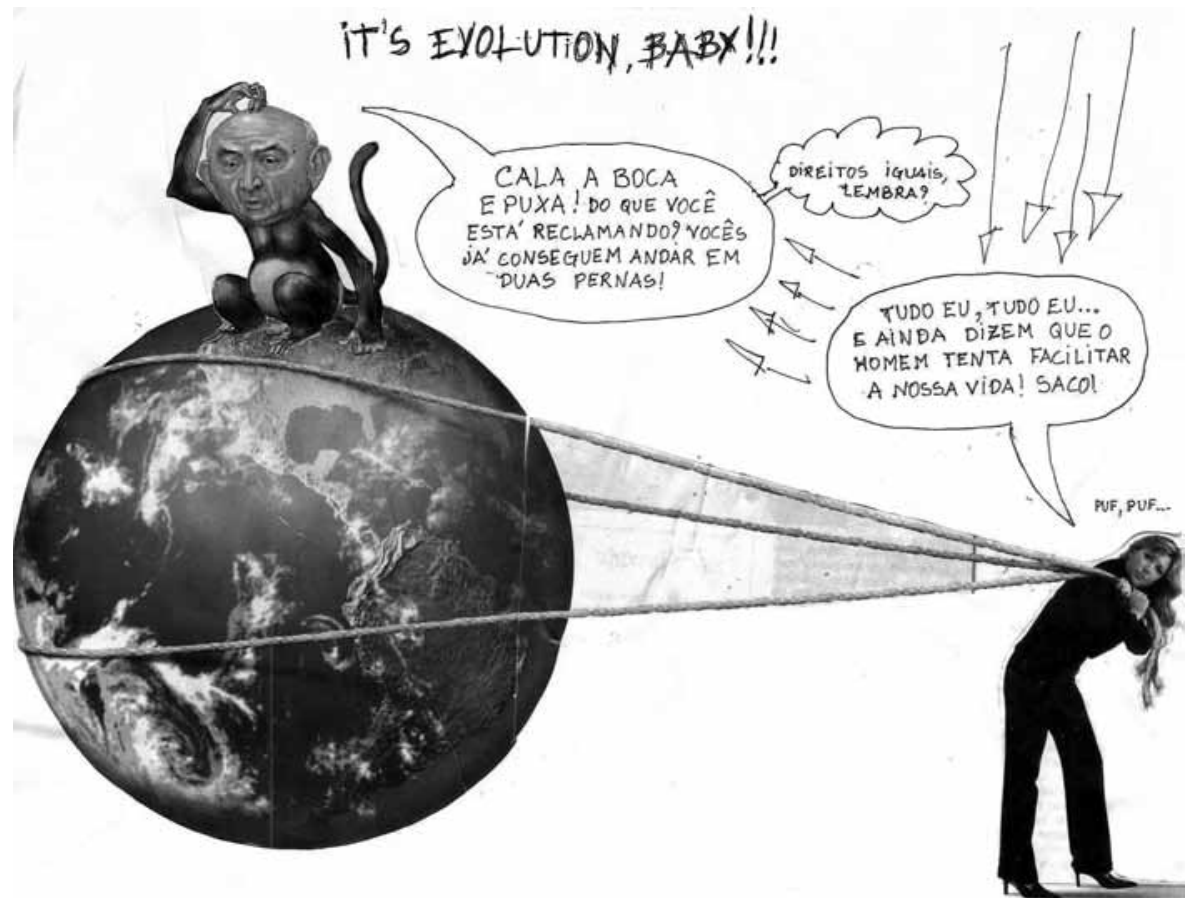

No intervalo que se seguiu disponibilizei reproduções digitais de várias obras da linguagem dos quadrinhos, em formas que incluem algumas fotonovelas, como as de Mojica Marins (O Estranho Mundo de Zé do Caixão). O objetivo da última proposta era, então, o trabalho narrativo com a fotografia, incluindo aí questões cênicas, com a atuação dos próprios participantes.

Aranha realizou uma fotonovela com acabamento gráfico semelhante ao da anterior, adaptando a crônica de Paulo Mendes Campos "Os Diferentes Estilos", com atuação sua e de pessoas de seu convívio. Nota-se nesta obra uma forte preocupação cênica, com elementos como a expressividade das atuações, figurino e iluminação, onde as cores criam as atmosferas de cada situação. Talvez pela natureza do texto que foi adaptado, ocorre uma menor preocupação em experimentar a diagramação, a ordem e diferenças de tamanhos e orientação dos quadrinhos na página, considerando as possibilidades expressivas deste uso. 


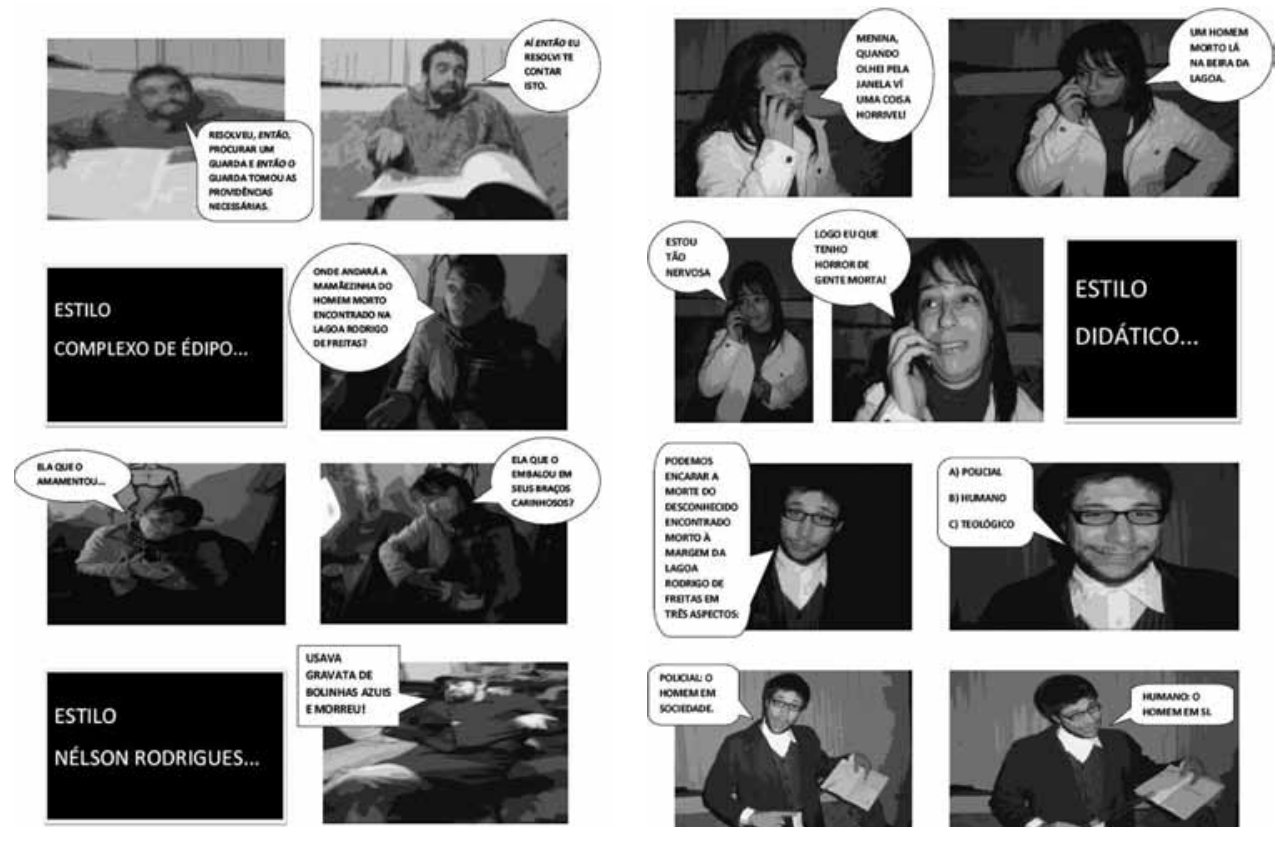

Figuras 14 e 15 Páginas da fotonovela de Aranha
Ao reunirmos os outros quatro membros do grupo para discutirmos as ideias para uma fotonovela coletiva, Riko expôs suas idéias de como unir todas as histórias em uma só: um conto que entrecruzaria assassinatos involuntários, ambientados na CEU II, a Casa do Estudante Universitário do Campus da UFSM.

Seguiu-se uma etapa mais difícil: com o semestre se aproximando de seu fim, todos os participantes tinham poucos intervalos para seguir o trabalho. Reuni-me aos poucos com cada um ou dois deles, e fomos construindo a narrativa. O participante Jonas e eu fomos editando conforme tínhamos material, e as quatro páginas da história ficaram prontas. Algumas destas cenas foram montadas em softwares de edição de imagens: por exemplo, as cenas do participante Fres fazendo manobras no skate constituem-se numa apropriação de fotos antigas dele com as intervenções digitais dos outros dois personagens e da casca de banana, numa estética que, por consenso e certa falta de domínio técnico, encontra referências nos efeitos visuais da famosa série de Chapolin Colorado, do mexicano Roberto Gómez Bolaños, que foi transmitida no Brasil desde os anos 1980 pela emissora SBT e parodiava histórias de heróis norte-americanos e europeus num contexto latino-americano. 

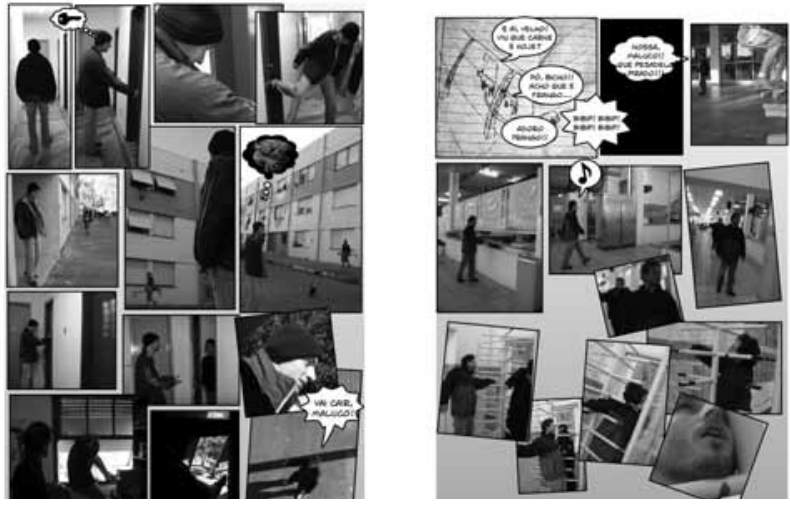

Discutimos, também, nestes encontros, o formato do zine e as histórias que nele estariam contidas. As ideias para a distribuição deste vão desde os meios digitais até um comércio informal de impressões ou fotocópias em preto e branco, divididas dentro de três exemplares de um número relativamente reduzido de páginas, em formato $\mathrm{A}_{5}$ ( $\mathrm{A}_{4}$ dobrada e grampeada). Tendo em vista a valorização das cores utilizadas e a crescente tendência da sociedade de baixar os artefatos culturais em vez de comprar, o formato escolhido ao final foi a disponibilização eletrônica, em arquivos de formato Adobe $p d f$, para os participantes através de e-mail e para o público em geral no endereço virtual utilizado para divulgação de minha pesquisa artística (http://symptomamundi.blogspot.com/2009/o8/httpwww.html), sob o título de CEUZine, por se tratar de uma produção realizada em sua maior parte na Casa do Estudante Universitário (CEU I e II-UFSM).

\section{Considerações sobre a investigação}

Muito do que planejei foi modificado no decorrer do trabalho, um pouco foi suprimido, mas a experiência foi mesmo assim recompensadora. Numa breve comparação com o trabalho desenvolvido em meu Estágio Supervisionado, de propostas semelhantes, noto que, por serem mais próximos de minha faixa etária, estes participantes possuem maior contato com os quadrinhos do que os adolescentes dos outros ambientes desta pesquisa, que parecem ter mais familiaridade com as linguagens da cibercultura e da aparentemente imbatível mídia televisiva, por mais atravessadas que estas sejam pela estética dos quadrinhos. Daí, constatei a maior fertilidade desta abordagem em ambientes não-formais, e a necessidade de criar outros enfoques para a docência escolar.
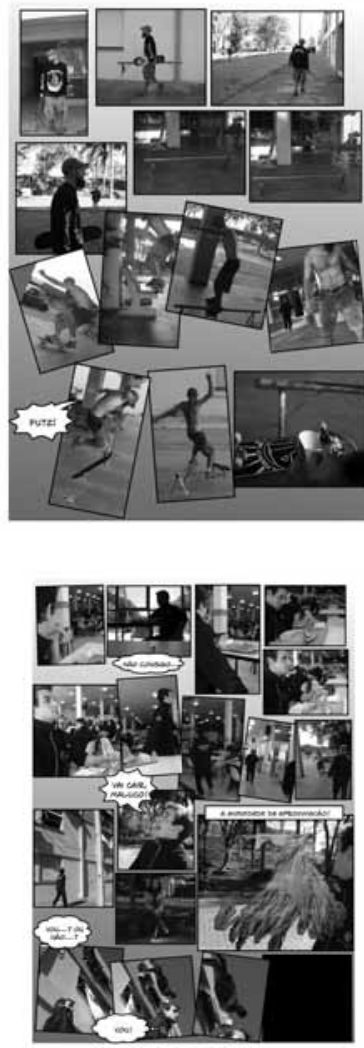

Figuras 16 a 19

Fotonovela coletiva por Jonas, Riko, Fres e Matheus 
Trocamos experiências, conhecemos novos artefatos culturais e novos pontos de vista, ouvimos como cada história tocou o imaginário do outro e também expomos nossos próprios percursos: práticas que conduzem à problematização dos papéis da educação e da mídia em nossas individualidades. A questão partir do cotidiano parece contemplada, a partir do momento em que todos escolheram como cenários locais familiares a eles, e como temáticas questões que os motivam em suas próprias experiências de vida. Ao mesmo tempo em que expressavam seus anseios, pensavam importantes questões da arte e da cultura visual.

Prefiro não considerar este trabalho finalizado. Com o potencial inventivo e expressivo demonstrado por este grupo, será um grande aprendizado seguir construindo tal espaço de debate e criação entre outras pessoas que também possuam interesse pelo assunto. Projeta-se, assim, uma espécie de ateliê de produção de narrativas visuais, que pode seguir publicando, por meios virtuais ou impressos, futuros zines de proposta semelhante ao aqui relatado, proporcionando a esta pesquisa um crescimento em diversidade e atividade.

\section{Referências Bibliográficas}

BARBOSA, Ana Mae. Zig/Zag, Arte/Educação e mediação. In: XX Seminário Nacional de Arte e Educação, 2006, Montenegro. XX Seminário Nacional de Arte e Educação. Montenegro : FUNDARTE, 2006. v. 1. p. 8-9.

CAMPOS, Paulo Mendes. Os Diferentes Estilos. Crônica. In: BRAGA, Rubem et al. Para Gostar de Ler. 9. ed. São Paulo: Ática, 1998, v.4.

CHARRÉAU, Leonardo. Imagem Global e Cultura Visual: Sobre o que se pode aprender no espaço midiático. Congresso Internacional: A Unicidade do Conhecimento. Universidade de Évora, 17 - 19 Maio de 2007.

CIRNE, Moacy. A explosão criativa dos quadrinhos. Petrópolis: Vozes, 1970.

. A linguagem dos quadrinhos: O universo estrutural de Ziraldo e Mauricio de Souza. Petrópolis: Vozes, 1971.

CORRÊA, Guilherme Carlos. Educação Comunicação Anarquia. Procedências da Sociedade de Controle no Brasil. São Paulo: Cortez, 2006.

EISNER, Will. Narrativas Gráficas. Trd. Leandro Luigi. São Paulo: Devir, 2005 
GRAWUNDER, Maria Zenilda. A Palavra Mascarada: Sobre a Alegoria. Santa Maria: UFSM, 1996.

HERNÁNDEZ, Fernando. Cultura Visual: mudança educativa e projeto de trabalho. Porto Alegre: Artes Médicas Sul, 2000.

KAPPAUN, Ivan Jéferson. Histórias em Quadrinhos: Uma Alternativa para o Ensino da Arte no Ensino Médio. Monografia, UFSM. Santa Maria: Janeiro de 2008.

MARCONDES, Maria Inês. Abordagem qualitativa e formação dos professores: da pesquisa para a prática de ensino. In: XIV ENDIPE, p. 459 a 472. Porto Alegre, PUC-RS, 2008.

MARINS, José Mojica. O Fabricante de Bonecas. Fotonovela. Roteiro de Rubens F. Lucchetti, fotografias de Luís Fideli Barreira. In: O Estranho Mundo de Zé do Caixão nํㅗ. São Paulo: Prelúdio, 1969, pp. 35-47.

MARTINS, Joel. A pesquisa qualitativa. In: FAZENDA, Ivani. (org.) Metodologia da pesquisa educacional. São Paulo: Cortez, 2006.

MCCLOUD, Scott. Desvendando os Quadrinhos. Trd. Hélcio de Carvalho, Marisa do Nascimento Paro. São Paulo: Makron Books, 1995.

Recebido em: 30/o8/10

Aceito em: 22/10/10

\section{FÁBIO PURPER MACHADO}

purper@ymail.com

É formado na Licenciatura em Artes Visuais e cursa o Bacharelado em Artes Visuais e a Especialização em TICs Aplicadas à Educação na UFSM. É membro do GEPAEC (Grupo de Estudos e Pesquisa em Arte, Educação e Cultura) e do Coletivo de ações artísticas (Des)Esperar, e bolsista do Programa Somar/Terra Sol, trabalhando com ilustrações, design gráfico e edição digital de vídeo.

\section{AYRTON DUTRA CORREAA}

É Doutor em Educação/UNICAMP (1999), Pós-doutor em ArteEducação/USP (2003). Atua na UFSM desde 1975, é coordenador do PPGAV (Programa de Pós-Graduação em Artes Visuais), onde orienta na linha de pesquisa Arte e Visualidade. 